\title{
EXPERIMENTAL AND NUMERICAL INVESTIGATION OF SINKHOLE DEVELOPMENT AND COLLAPSE IN CENTRAL FLORIDA
}

Xiaohu Tao

Geophysical Fluid Dynamics Institute, Florida State University, Tallahassee, FL, 32306

College of Water Conservancy and Hydropower Engineering, Hohai University, Nanjing, Jiangsu, 210098, P.R. Chi-

na,taoxiaohu_hhu@126.com

Ming Ye

Department of Scientific Computing and Geophysical Fluid Dynamics Institute, Florida State University, Tallahassee, FL 32306, U.S.A, mye@fsu.edu

\section{Dangliang Wang}

Department of Scientific Computing and Geophysical Fluid Dynamics Institute, Florida State University, Tallahassee, FL 32306,U.S.A,dlw9800@163.com

\section{Roger Pacheco Castro}

Department of Scientific Computing and Geophysical Fluid Dynamics Institute, Florida State University, Tallahassee, FL 32306,U.S.A, matbnt@gmail.com

\section{Xiaoming Wang}

Department of Mathematics and Geophysical Fluid Dynamics Institute, Florida State University, Tallahassee, FL 32306,U.S.A, xwang@fsu.edu

\section{Jian Zhao}

College of Water Conservancy and Hydropower Engineering, Hohai University, Nanjing, Jiangsu, 210098, P.R. China,zhaojian@hhu.edu.cn

\section{Abstract}

The mechanisms of sinkhole formation, development, and collapse are investigated in this study using experimental and numerical methods. Sandbox experiments are conducted to understand how excessive groundwater pumping triggers sinkholes formation. The experimental results indicate that the change of hydrologic conditions is critical to sinkhole development. When seepage force increases due to increase of hydraulic gradient, clay and sand particles start moving downward to form a cavity. The confining unit is of particular importance because the cavity is first formed in this layer. Based on the conceptual model developed from the sandbox experiments, the Fast Lagrangian Analysis of Continua (FLAC) code and Particle Flow Code (PFC) are coupled to simulate the sandbox experiments. PFC was used to simulate particle movement in the sinkhole area, and FLAC is used for other areas. While the current numerical simulation can simulate the experiment results such as the sizes of the cavity and the sinkhole, the simulation capability is limited by the computing cost of PFC. More effort of model development is necessary in the future study.

\section{Introduction}

Sinkholes are a common geological feature of karst landscape in Florida, southeastern United States, and worldwide. In particular, cover-collapse sinkholes occur abruptly and can cause catastrophic damages such as death, injury, and property damage. In Florida, a Tampa resident vanished into a sinkhole that opened under his bedroom on a night in March, 2013. In the last several years, sinkholes have become Florida's insurance disaster due to sinkhole collapse in urban areas. Covercollapse sinkholes also do severely damage buildings, drain farm ponds, damage roads, and wreck farming equipment, and lead to engineering and environmental problems (Beck, 1988). There is an urgent need to understand the mechanisms of sinkhole development and catastrophic collapse.

Cover-collapse sinkholes occur in the soil or other loose material overlying soluble bedrock. The thickness and cohesiveness of the soil cover determine the size of a cover-collapse sinkhole. Figure 1 shows a typical process of cover-collapse sinkholes formation caused by excessive groundwater pumping. A karst aquifer is the 


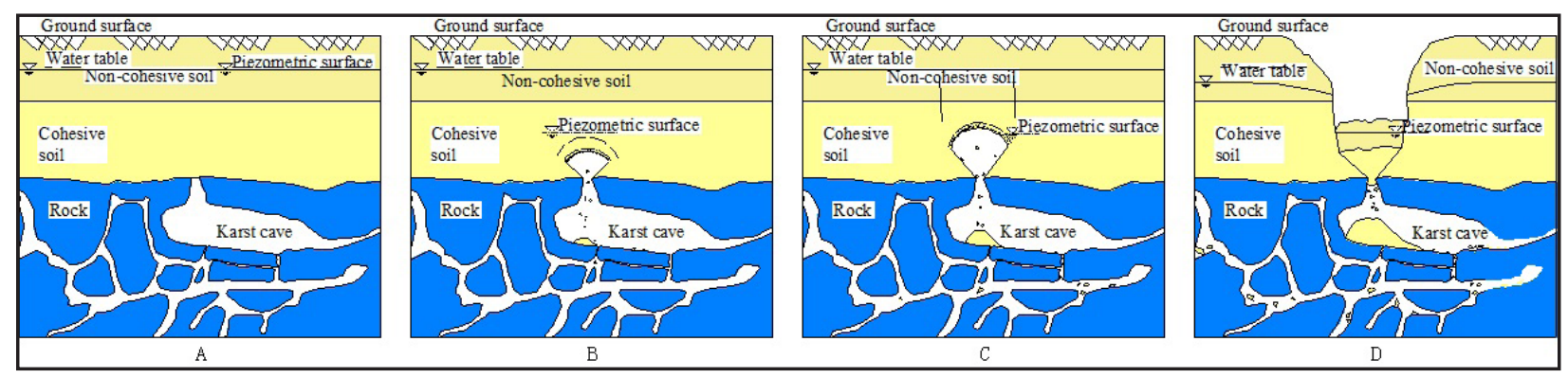

Figure 1. Model for cover-collapse sinkhole.

pre-requisite, and sinkhole development always starts from dissolution of soluble rocks or fractures and conduits to create an opening, which provides a passage for soil transport downward. Groundwater is one of the primary triggering mechanisms for sinkhole development and collapse, because seepage force due to groundwater flow drags clay and sand particles downward. Figure 1(A) shows two layers with cohesive and non-cohesive soil; the cohesive soil layer overlies the karst bedrocks and is beneath the non-cohesive soil layer, which is common in central Florida. In the initial stage of sinkhole development, an opening forms in the rock at the interface between the bed rock and cohesive soil. While the piezometric surface is higher than the water table in the initial stage, after excessive pumping starts, the piezometric surface decreases (Figure 1(B)) and downward groundwater flow is created. Subsequently, sediment in the cohesive soil layer starts falling down due to gravitational force and seepage force applied on the particles (Figure 1(B)). This forms a cavity in the cohesive layer. The cavity gradually increases, and it in turn increases hydraulic gradient and thus seepage force. Because of these, the cavity expansion accelerates (Figure 1(C)). Once the cavity expands to the non-cohesive soil layer, sand movement becomes dramatic. When the non-cohesive soil layer cannot support the overlying material, collapse occurs and a sinkhole propagates to land surface (Figure 1(D)).

While the process of cover-collapse sinkhole formation triggered by groundwater pumping has been understood, mathematical models and numerical modeling tools have not been available for predictive understanding. A coupled model based on FLAC and PFC was used to simulate the soil-structure interactions during a sinkhole event (Caudron et al., 2006). Ahmed (2013) used finite element analyses to detect three-dimensional (3-D) deformations due to submerged cavities that lead to sinkhole. Tharp (2003) employed an elastic-plastic model to demonstrate the development of a sinkhole above a karst cavity. Shalev (2012) adopted a two-dimensional (2-D) visco-elastic model to simulate the sinkhole formation to take into account of the brittle and ductile aspects of sinkhole collapse. Baryakh et al. (2009) established a numerical model that uses the discrete element method to simulate the evolution of the stress-strain state of a rock mass containing a karst cavity. Baryakh and Fedoseev (2011) also set up a finite element model of a growing cavern to describe possible scenarios of sinkholes development in the karstic areas, to determine formation criteria for ground surface sinkholes and underground caverns, and to estimate sinkhole and cavern sizes. Shalev et al. (2006) simulated the dissolution of salt layer and the creation of cavities using the finite element methods. The numerical simulation showed the growth of cavities from the bottom to the top of the salt layer, and suggested that sinkhole collapses shortly after the cavities reach the top of the salt layer. These modeling effort suggests that, while the continuum theory can estimate the stressstrain state of sinkhole events, it is difficult to take into account the change of cavity geometry such as enlargement of the cavity in the cohesive soil layer. While discontinuum theories can be used to resolve this problem, the dis-continuum theories are computationally intensive and not always practically affordable.

\section{Sandbox Experiment}

Sandbox experiments are conducted to better understand the process of sinkhole development and collapse. Figure 2 shows the schematic view of experiments. A sandbox of $150 \mathrm{~cm} \times 120 \mathrm{~cm} \times 20 \mathrm{~cm}$ was constructed with plastic material. There are four tanks to control the water level of unconfined and unconfined aquifer. As shown in Figure 3, the sandbox was filled with three different hydrogeological materials in three layers. The bottom one (in black) represented a karst aquifer with void space. A clay layer (in yellow) overlaid the karst layer to represent a confining layer. Between the two layers, three opening were designed, but only the one of $1 \mathrm{~cm}$ in the middle was used in this study to create a sinkhole in the middle of the sandbox. Above the clay layer was a sand layer (in grey) to represent an unconfined aquifer. 


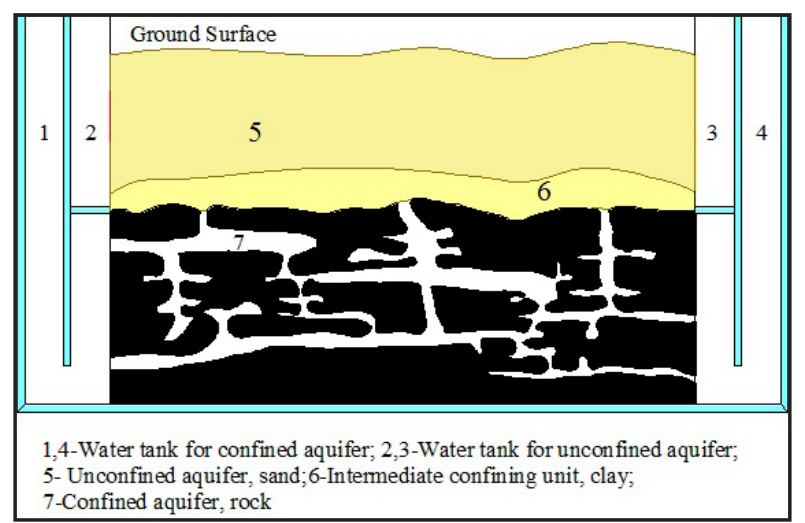

Figure 2. Schematic of sandbox experiments.

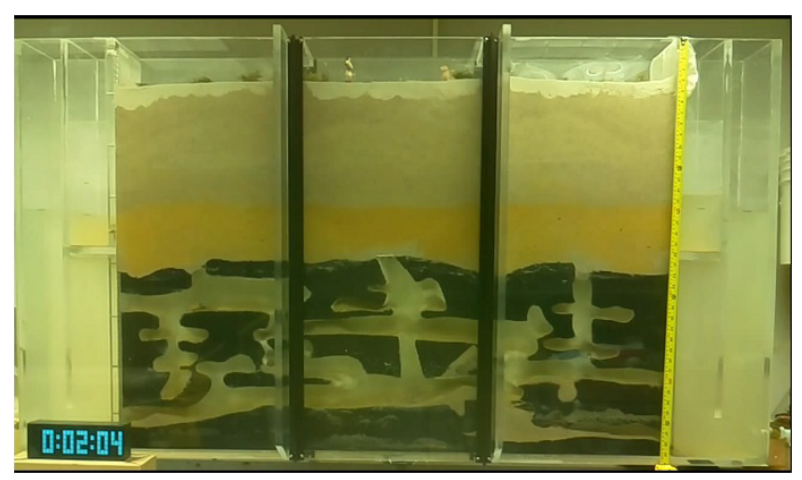

Figure 3. Photo of sandbox experiments.

Hydraulic head of the unconfined aquifer was controlled by the inner reservoirs at the both sides of the sandbox. The outer reservoirs were used to control hydraulic head of the confined aquifer.

The sandbox experiments are designed to understand impacts of groundwater pumping on sinkhole development and collapse. The impacts are believe to be the major reasons for the sinkhole events in the Dover/Plant City area during the winter of 2010, when more than 100 sinkhole collapses were triggered by excessive groundwater pumping for irrigation to prevent crops from being frozen. The sandbox experiments start by lowering hydraulic head in the confined layer to mimic a pumping scenario. The water level in the unconfined aquifer remains constant. After the drop of hydraulic head in the confined aquifer, a small amount of clay particles moves downward through the opening due to the seepage force caused by hydraulic gradient between the unconfined and confined layers. A cavity starts to form in the clay layer, and slowly expands upward. Once the cavity reaches the sand layer, sinkhole development is accelerated, and sinkhole collapse occurs shortly because of small cohe-

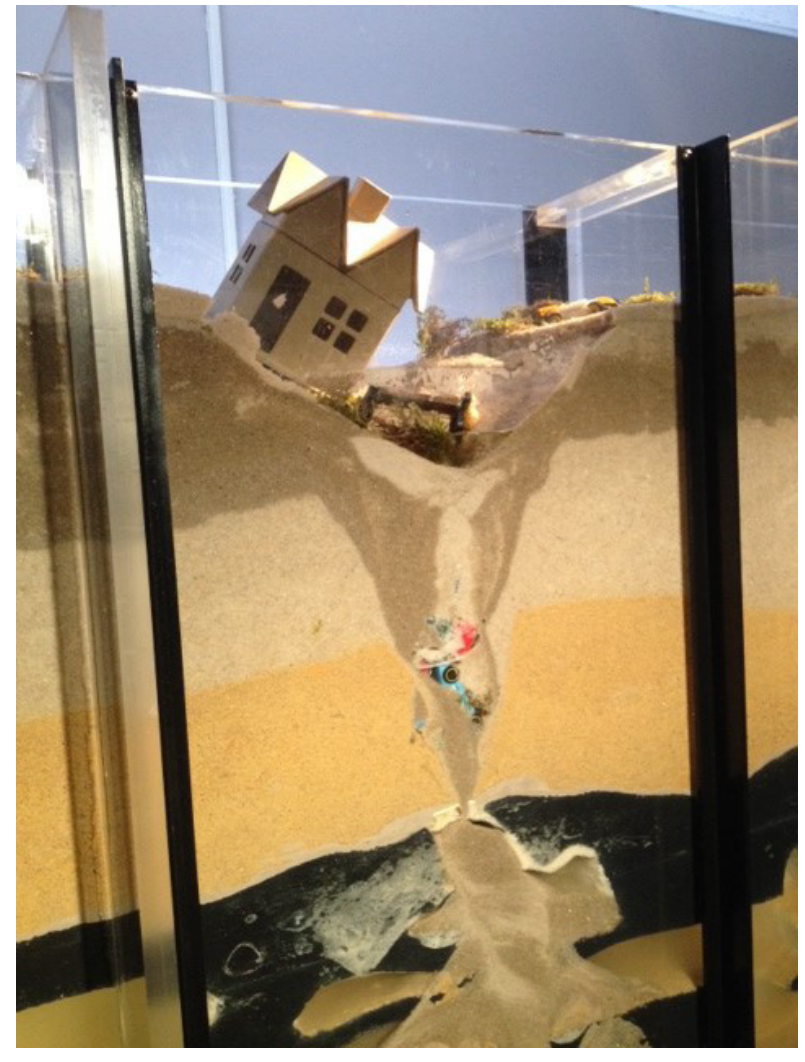

Figure 4. Sinkhole collapse in a sandbox experiment.

sion of the wet sand. Figure 4 shows the picture after sinkhole collapse.

\section{FLAC/PFC coupling approach}

In this study, we use the continuum and dis-continuum theories together by coupling the finite difference code, FLAC, based on the continuum theories with the discrete element code, PFC, based on the dis-continuum theories (both FLAC and PFC are developed by the Itasca Consulting Group, Inc.). Since PFC is computationally demanding, it is only used for the small area of excessive displacement above the opening. FLAC is less computationally demanding, and thus used to simulate the larger area of small deformation away from the opening. Using the coupled FLAC/PFC approach minimizes the computational requirement for simulating the process of sinkhole development and collapse.

\section{Coupling FLAC and PFC}

The coupling of FLAC and PFC is realized by exchanging displacements, velocities, and forces at each modeling step. The data exchange is made possible by the I/O socket connection ability to pass data rapidly between 
the two codes running on the same machine or on separate machines with a network connection. As shown in Figure 5, the data exchange is two-directional between FLAC and PFC. In each step of numerical simulation, the velocity at the interface between FLAC and PFC model domains (Figure 6) are first obtained from the FLAC run and then sent to PFC via the I/O socket. After receiving the data from FLAC, PFC starts to update the forces at the interface and then send the results of forces back to FLAC via the I/O socket. Afterward, the simulation moves to the next time step, and the iteration continues until the end of simulation time.

\section{Numerical simulation}

Table 1 lists the values of the parameters used for the numerical simulation. While the clay/sand particle movements change hydraulic conductivity, to simplify the numerical simulation, it is assumed that the deformation

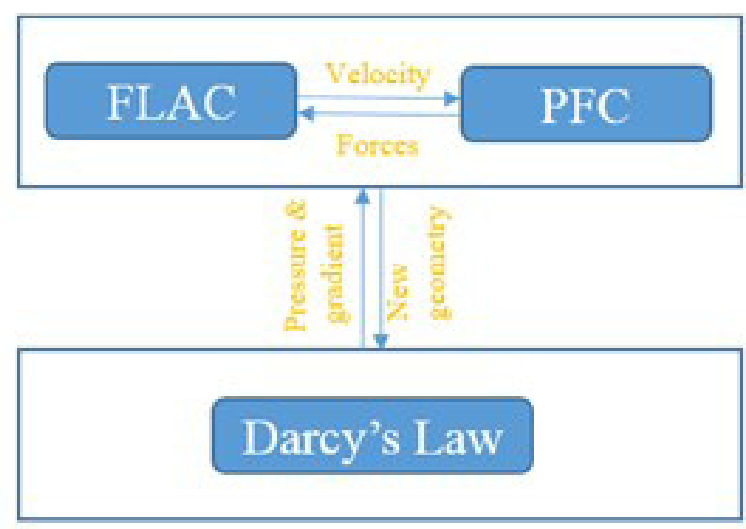

Figure 5. Coupling of FLAC, PFC, and groundwater flow modeling. and the particle transport have negligible effect on the hydraulic conductivity and that hydraulic conductivity is constant during the process of sinkhole development. The groundwater flow of the entire domain is simulated using the Darcy's Law and heat equation.

The FLAC/PFC simulation is set up as shown in the sketch map of Figure 6. Zero horizontal displacements are assumed at the side boundaries, and zero vertical displacements at the bottom boundary in the FLAC modeling area. For the PFC modeling area, the bottom boundaries are the two walls (Figure 6) with the distance of $1 \mathrm{~cm}$. At the initial time, the model is in the steady state with the hydraulic head of $0.45 \mathrm{~m}$ (the datum is at the bottom of clay layer) for the confined aquifer and $0.4 \mathrm{~m}$ for the unconfined aquifer (sand layer).

The simulation starts by dropping the piezometric surface $0.1 \mathrm{~m}$ rapidly to create unsteady flow and particle movement. During each time step of the flow modeling, hydraulic pressure and pressure gradient is calculated and then passed to the FLAC-PFC-based mechanical

\begin{tabular}{|c|c|c|}
\hline Variables & Clay & Sand \\
\hline Density $(\mathrm{Kg} / \mathrm{m} 3)$ & 2200 & 2600 \\
\hline Bulk modulus $(\mathrm{Pa})$ & $7.00 \mathrm{E}+05$ & $1.30 \mathrm{E}+07$ \\
\hline Shear modulus $(\mathrm{Pa})$ & $4.00 \mathrm{E}+05$ & $8.00 \mathrm{E}+06$ \\
\hline Cohesion $(\mathrm{Pa})$ & $8.00 \mathrm{E}+05$ & 0 \\
\hline Friction angle $\left({ }^{\circ}\right)$ & 25 & 35 \\
\hline Hydraulic conductivity $(\mathrm{m} / \mathrm{s})$ & $1.00 \mathrm{E}-08$ & $5.00 \mathrm{E}-05$ \\
\hline
\end{tabular}

Table 1. Parameter values of soil properties

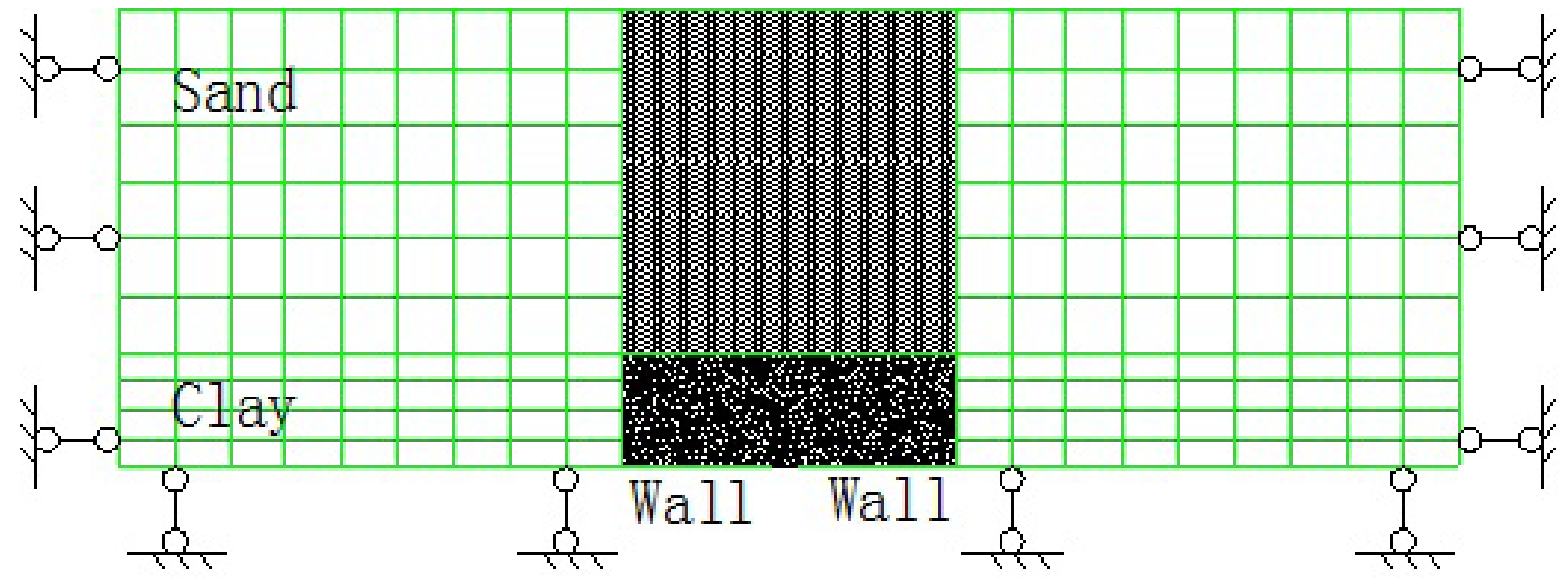

Figure 6. Illustration of modeling domain. PFC is used for the black area, and FLAC is used for rest of the area. 
modeling (Figure 5). The time step used in the mechanical modeling is smaller than the time step used in the flow modeling. The mechanical modeling yields new cavity geometry due to particle movements. The new cavity geometry (i.e., the cavity boundary) is passed to the flow simulation for seepage calculation (Figure 5).

\section{Results of Numerical Simulation}

For the flow simulation, the time step of 1 second is selected, and the time step of the mechanical modeling is significantly smaller but determined by FLAC and PFC. A total of 20,000 particles are used for simulating the clay layer and 8,000 particle for the sand layer. The simulation results at the time of $1 \mathrm{~s}, 3 \mathrm{~s}, 5 \mathrm{~s}, 8 \mathrm{~s}$, and $15 \mathrm{~s}$ are selected for analyzing the cavity expansion and the hydraulic head distribution.

\section{Cavity expansion}

Figure 7 shows the cavity in the clay layer obtained in a sandbox experiment and at $\mathrm{t}=3 \mathrm{~s}, 8 \mathrm{~s}$, and $15 \mathrm{~s}$ of the
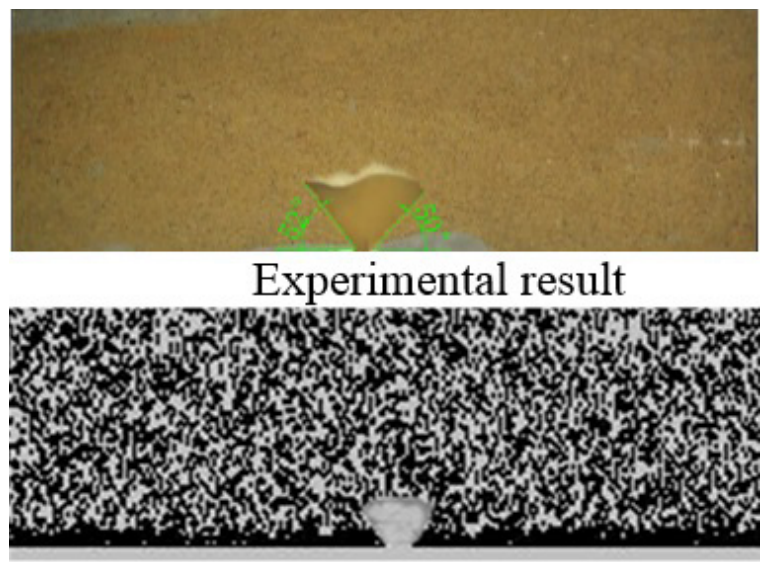

$$
\mathrm{t}=3 \mathrm{~s}
$$
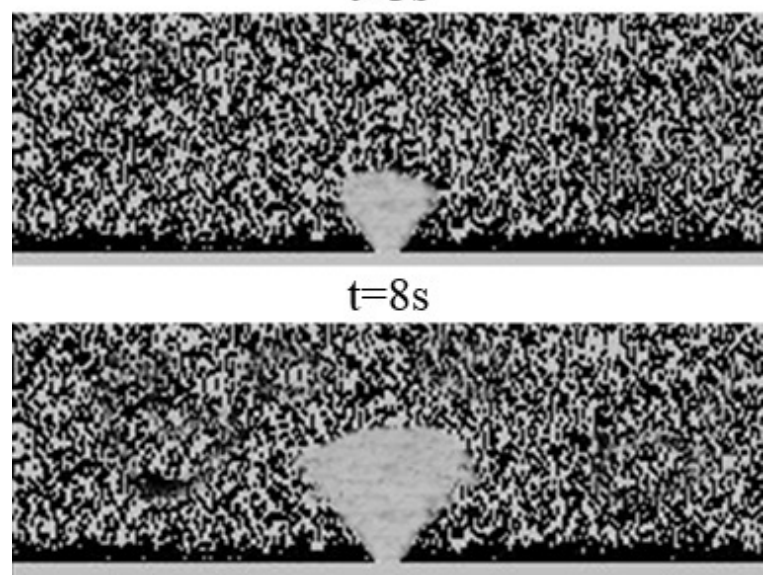

Figure 7. Cavity in the clay layer obtained in a sandbox experiment (top) and numerical simulation at $t=3 \mathrm{~s}, 8 \mathrm{~s}$, and $15 \mathrm{~s}$. numerical simulation. The numerical modeling is able to simulate expansion of the cavity. The shape of the simulated cavity is similar to that of the experimental cavity. For example, the angles between the experimental cavity side boundary and the horizontal direction are about $49^{\circ} \sim 50^{\circ}$ (Figure 7), and the corresponding angles of the simulated cavity are about $48^{\circ} \sim 54^{\circ}$.

\section{Hydraulic pressure and head}

Figure 8 shows the vertical profile of hydraulic pressure along the vertical line perpendicular to the opening at the interface between the confining layer and the confined layer. While the pressure profile in the unconfined layer of sand does not change with time, the pressure profile in the confining layer changes dramatically over time, in particular in the early time when the sinkhole starts forming. The pressure change has substantial impacts on cavity geometry and expansion. At the beginning of cavity formation the largest hydraulic gradient occurs at the point of the opening, and it induces a large seepage force on the particles and causes downward movement of clay particles. As a result, the cavity will expand upward to the sand layer until sinkhole collapse. The pressure change in the confining layer happens not only above the opening but at its vicinity, as shown in Figure 9 that plots the spatial distribution of hydraulic head in the entire modeling domain of confining and unconfined layers.

These results indicate that, during the process of sinkhole formation, monitoring hydraulic pressure and hydraulic head in the unconfined layer is not useful, because the two quantities do not change with time. The reason is that the clay layer isolates the pressure propagation to the unconfined layer. When the cavity is expanded to the sand layer pressure change in the layer may be reflected

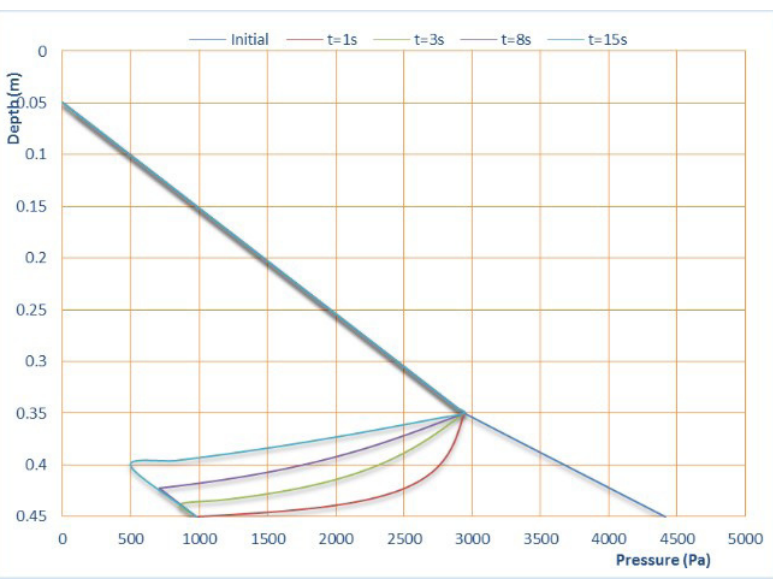

Figure 8. Vertical profiles of hydraulic pressure at different simulation times. 


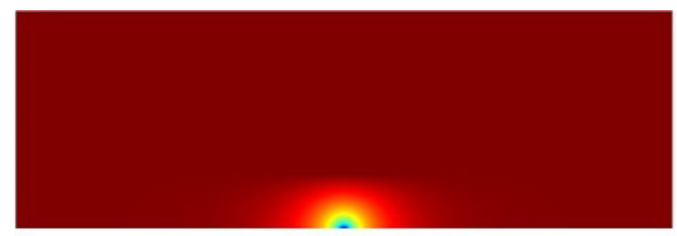

$\mathrm{t}=1 \mathrm{~s}$

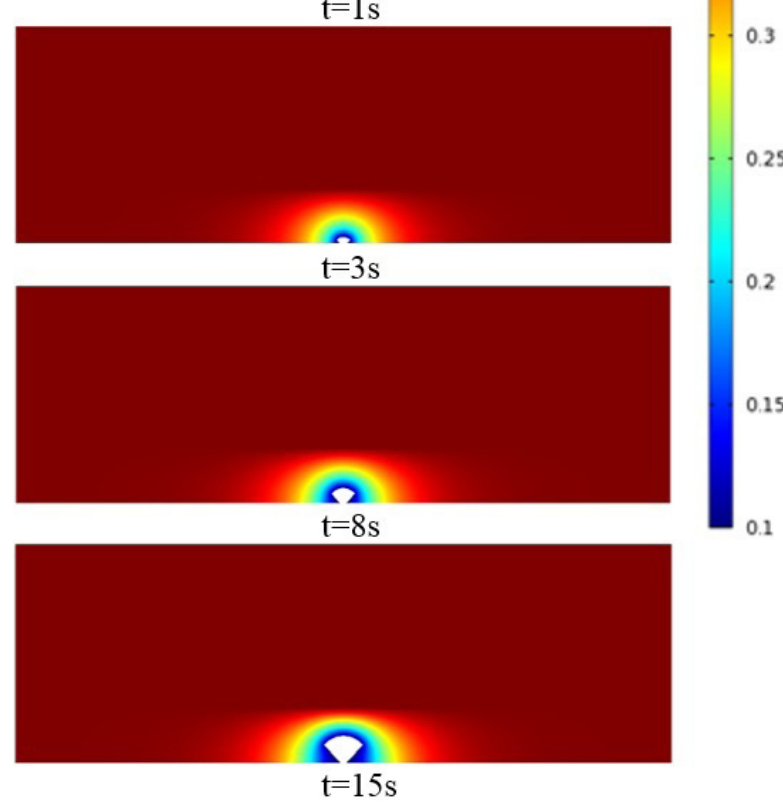

Figure 9. Spatial distribution of simulated hydraulic head $(\mathrm{m})$ at $t=1 \mathrm{~s}, 8 \mathrm{~s}$, and $15 \mathrm{~s}$.

in monitoring wells of the unconfined layer. However, at this stage, the sinkhole has been largely formed, and the monitoring data of the unconfined layer is less useful than the monitoring data of the confining layer. The challenge is to determine where to install monitoring well in the confining layer.

\section{Conclusions}

This paper presents a laboratory study for understanding the processes of sinkhole formation, development, and collapse. The experiments are useful not only to illustrate the sinkhole processes but also to develop a conceptual model for mathematical and numerical modeling. The experiments indicate that the confining layer of clay is important to sinkhole formation and development. This paper also demonstrates an approach that uses FLAC and PFC to simulate the laboratory experiments. The results of the numerical simulation are consistent with the phenomena observed in the experiments, in particular the expansion of the cavity due to particle movement caused by the increase of seepage force after hydraulic head in the confined layer drops. The confining layer is of particular importance, because the cavity is first formed in this layer. It is important to monitor pressure change in the confining layer for detection of sinkhole in its early formation. More effort is warranted to develop more robust numerical models for simulating sinkhole events in the future research.

\section{Acknowledgements}

This research is funded by FSU MultiDisciplinary Support. The first and the third authors were supported by the China Scholarship Council for their study at FSU. The fourth author was supported by the Fulbright Scholarship of the U.S. Department of State.

\section{References}

Ahmed M. 2013. Experimental and Numerical Modeling of Sinkhole Collapse. In: Proceedings of the Transportation Research Board 92nd Annual Meeting, 13-17 Jan 2013. Washington, D.C.

Baryakh AA, Rusin EP, Stazhevsky SB. 2009. Stressstrain state of karst areas. J Min Sci 45 (6): 517524.

Baryakh AA, Fedoseev AK. 2011. Sinkhole formation mechanism. J Min Sci 47 (4): 404-412.

Beck BF. 1988. Environmental and engineering effects of sinkholes - the processes behind the problems. Environ Geol Water Sci. 12 (2): 71-8.

Caudron M, Emeriault F, Kastner R. 2006. Collapses of underground cavities and soil-structure interactions: experimental and numerical models; proceedings of the Proceedings of the 1st Euro mediterranean symposium on advances on geomaterials and structures, 3-5 May 2006, Hammamet, Tunisia.

Shalev E, Lyakhovsky V. 2012. Viscoelastic damage modeling of sinkhole formation. Journal of Structural Geology. 42 (0): 163- 70.

Shalev E, Lyakhovsky V, Yechieli Y. 2006. Salt dissolution and sinkhole formation along the Dead Sea shore. Journal of Geophysical Research: Solid Earth 111(B3): B03102.

Tharp T. 2003. Cover-collapse sinkhole formation and soil plasticity. In: Beck BF, editor. Sinkholes and the engineering and environmental impacts of karst; 6-10 Sept. 2003; Huntsville, Alabama. ASCE Publishing. p. 110-123. 